\title{
Heartbeat: principles for excellence in development of clinical guidelines
}

Clinical guidelines have become a core element in optimising care for patients with cardiovascular disease. However, the quality of guidelines depends on a rigorous unbiased process that integrates the clinical evidence with input from a range of stakeholders. In this issue of Heart, Garbi ${ }^{1}$ summarises the National Institute for Health and Care Excellence (NICE) principles and processes for development of clinical guidelines in England. The discussion is divided into four key areas: (1) Guideline development by an independent advisory committee includes aligning recommendations with national health policies, and involvement of patients, patient-advocates, and the public as well as healthcare professionals. (2) Recommendations should be based on relevant, reliable and robust evidence and should include consideration of cost-effectiveness and population benefit. (3) Guidelines should support innovation and reduce healthcare inequalities. (4) Finally, ensuring guideline implementation and providing regular updates are essential.

In the accompanying editorial, Otto, Kudenchuk and Newby ${ }^{2}$ compare the NICE methodology with the current approach of our cardiovascular professional societies, as well as to established reporting criteria for clinical practice guidelines (figure 1 ). ${ }^{3}$ They propose several areas for improvement including cooperative development of a common evidence database; a rigorous transparent process based on established standards; a more diverse group of stakeholders; minimising conflicts of interest; support by information specialists, medical writers and other relevant experts; regular updates; adaptation for regional considerations; and improved methods for dissemination and access. As they conclude: 'Current cardiovascular society guidelines fall short of best practice. We can and must do better.'

In patients with atrial fibrillation (AF) at moderate or high risk of stroke, randomised controlled trials (RCTs) have

Division of Cardiology, University of Washington, Seattle, Washington, USA

Correspondence to Professor Catherine M Otto, Division of Cardiology, University of Washington, Seattle,WA 98195, USA; cmotto@uw.edu

\section{Reporting Criteria for Clinical Practice Guidelines}

\begin{tabular}{|c|c|}
\hline Scope and Purpose & $\begin{array}{l}\text { - Objectives (prevention, screening, } \\
\text { diagnosis, Rx, etc.) } \\
\text { - Questions (interventions, outcomes) } \\
\text { - Target population and health care } \\
\text { setting }\end{array}$ \\
\hline Stakeholder Involvement & $\begin{array}{l}\text { - Writing group membership } \\
\text { - Target patient population } \\
\text { (preferences and views) } \\
\text { - Intended guideline audience }\end{array}$ \\
\hline Rigour of Development & $\begin{array}{l}\text { - Search methods } \\
\text { - Evidence selection criteria } \\
\text { - Strengths/limitations of evidence } \\
\text { - Formulation of recommendations } \\
\text { - Lenefits/harms consideration } \\
\text { recommendations } \\
\text { - External review (intent, methods) } \\
\text { - Update timeline and methodology }\end{array}$ \\
\hline Clarity of Presentation & $\begin{array}{l}\text { - Specific and unambiguous } \\
\text { recommendations } \\
\text { - Management options } \\
\text { - Key recommendations }\end{array}$ \\
\hline Applicability & $\begin{array}{l}\text { - Facilitators and barriers to application } \\
\text { - Implementation advice and tools } \\
\text { (summary documents, checklists, } \\
\text { algorithms, manuals, etc) } \\
\text { - Resource implications (cost } \\
\text { information) } \\
\text { - Monitoring/auditing criteria }\end{array}$ \\
\hline Editorial Independence & $\begin{array}{l}\text { Funding body } \\
\text { Competing interests }\end{array}$ \\
\hline
\end{tabular}

Figure 1 Visual summary of reporting criteria for clinical practice guidelines as detailed in the Appraisal of Guidelines, Research and Evaluation (AGREE) checklist.

shown superiority or non-inferiority of non-vitamin $\mathrm{K}$ oral anticoagulants (NOACs) over vitamin $\mathrm{K}$ anticoagulants (VKA) for prevention of stroke or systemic embolism along with reduced rates of intracranial haemorrhage. However, patients in RCTs may not be representative of the full range of patients seen in clinical practice. In order to address this issue, Camm and colleagues ${ }^{4}$ used a method called overlap propensity matching to compare the effectiveness of VKA and different NOACs for mortality, stroke/ systemic embolism and major bleeding in patients with newly diagnosed AF and an indication for oral anticoagulation. Based on 25551 patients in the Global
Anticoagulant Registry in the FIELDAtrial Fibrillation (GARFIELD-AF) study, they confirmed that 'Important benefits in terms of mortality and major bleeding were observed with NOAC versus VKA with no difference among NOAC subtypes' (figure 2).

In the accompanying editorial, Choi and Lee $^{5}$ point out the strengths of this study including a clinically diverse international patient cohort with regular audits and a low rate of loss to follow-up, a sophisticated matching method, and results consistent with previous RCTs. However, limitations include the possibility of residual confounders; possible discontinuation or switching of medications during 


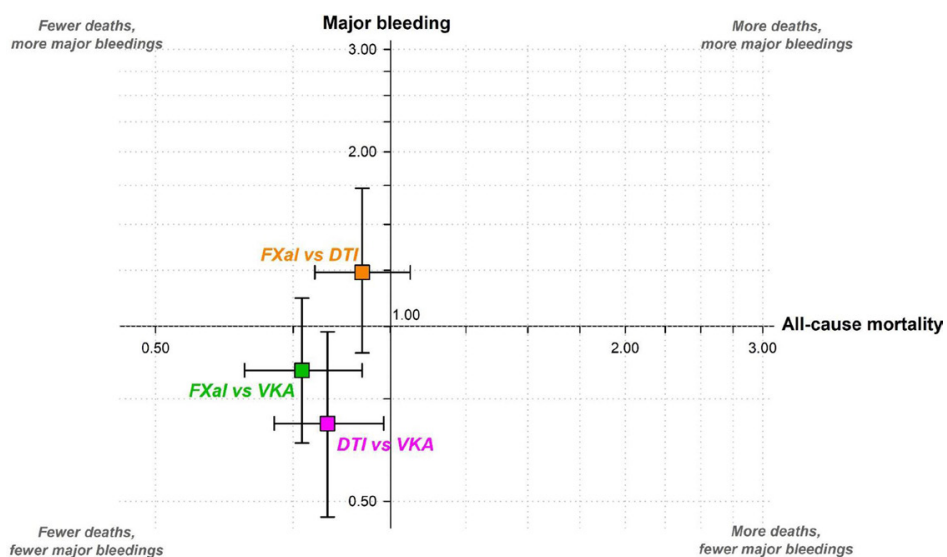

Figure 2 Adjusted* HRs and corresponding $95 \%$ Cls for selected outcomes at 2 years of follow-up by OAC treatment at baseline. The reference considered is the treatment reported as second. *Obtained using an overlap-weighted Cox model. Variables included in the weighting scheme are: country and cohort enrolment, sex, age, ethnicity, type of AF, care setting specialty and location, congestive heart failure, acute coronary syndromes, vascular disease, carotid occlusive disease, prior stroke/TIA/SE, prior bleeding, venous thromboembolism, hypertension, hypercholesterolaemia, diabetes, cirrhosis, moderate to severe chronic kidney disease , dementia, hyperthyroidism, hypothyroidism, current smoking, heavy alcohol consumption, body mass index (BMI) heart rate, systolic and diastolic blood pressure at diagnosis and baseline antiplatelet use. DTI, direct thrombin inhibitor; FXal, factor Xa inhibitors; NOAC, non-vitamin K oral anticoagulants; OAC, oral anticoagulants; SE, systemic embolism; TIA, transient ischaemic attack; VKA, vitamin K antagonists.

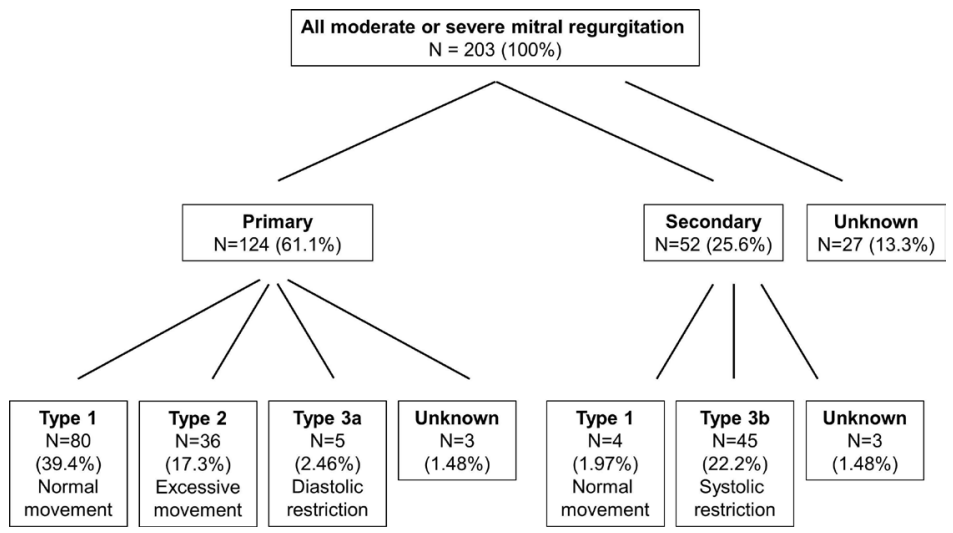

Figure 3 Mechanism of mitral regurgitation (MR). The mechanisms of valve dysfunction in patients with moderate or greater MR are shown, according to Carpentier classification. Type 1, normal leaflet motion and position; type 2, excess leaflet motion; type 3a, restricted leaflet motion in systole and diastole; type $3 \mathrm{~b}$, restricted leaflet motion in systole.

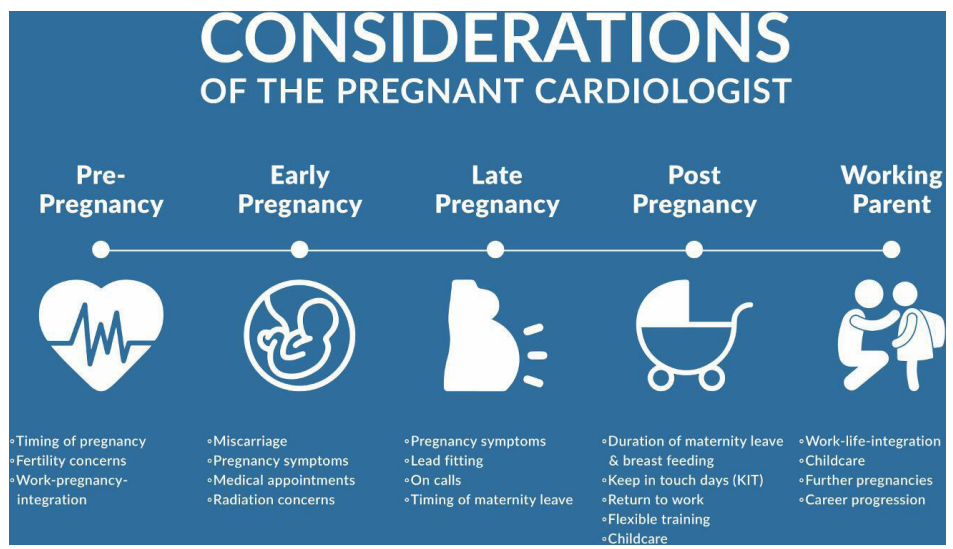

Figure 4 Concerns of the pregnant cardiologist. this study period; lack of detailed data on types of major bleeding, and regional or ethnic differences in outcomes; and any effects due to lack of adherence to therapy. As they conclude 'The GARFIELD-AF registry has reported valuable clinical practice patterns in AF worldwide, but it will also play a role as a pragmatic study for real-world practice-based RCTs.'

The prevalence and outcomes of adults over age 65 years with more than mild mitral regurgitation (MR) or tricuspid regurgitation (TR) was studied in 4755 subjects who had undergone echocardiography in the Oxford Valvular Heart Disease Population Study (OxVALVE). ${ }^{6}$ Overall, the prevalence of moderate or greater MR was $3.5 \%$ and TR was $2.6 \%$ with only about half these patients having previously diagnosed valve disease. Subjects with regurgitation identified by screening were less likely to be symptomatic than those with known valve disease. The aetiology of MR was most often primary although 22\% had secondary MR due to left ventricular systolic dysfunction (figure 3). Surgical intervention was rarely undertaken $(2.4 \%)$ during the 64-month median follow-up.

In an editorial, Bouleti and Iung $^{7}$ point out that the prevalence of MR and TR increases even further in those over age 75 years and that the number of patients with secondary MR and a low left ventricular ejection fraction is of concern given the association with impaired long-term survival. They conclude: 'These findings highlight the need for educational programmes to increase the awareness on heart valve disease, for evaluation of the adherence to guidelines and for the continuous development and evaluation of less invasive interventions targeting elderly patients.'

The Education in Heart article in this issue summarises the recommended approach to screening for cardiovascular disease in healthy individuals. ${ }^{8}$ A stateof-the-art review article on nuclear cardiology 9 provides an overview of myocardial perfusion imaging techniques and clinical applications for ischaemic heart disease, heart failure, and myocardial disease and infection. Newer nuclear imaging approaches include ${ }^{18} \mathrm{~F}$-fluorodeoxyglucose positron emission tomography scans for diagnosis of infective endocarditis, particularly in patients with prosthetic valves, and the use of nuclear approaches as adjuncts for the diagnoses of sarcoidosis and amyloidosis.

Our Cardiology in Focus series continues with an article ${ }^{10}$ on pregnancy during cardiology training which will be helpful 
for women considering pregnancy during cardiology training (or as a consultant cardiologist) for those providing training and support to those women (figure 4).

Funding The authors have not declared a specific grant for this research from any funding agency in the public, commercial or not-for-profit sectors.

Competing interests None declared.

Patient and public involvement Patients and/or the public were not involved in the design, or conduct, or reporting, or dissemination plans of this research.

Patient consent for publication Not required.

Provenance and peer review Commissioned: internally peer reviewed.

(C) Author(s) (or their employer(s)) 2021. No commercial re-use. See rights and permissions. Published by BMJ.

\section{D) Check for updates}

To cite Otto CM. Heart 2021;107:937-939.

Heart 2021;107:937-939.

doi:10.1136/heartjnl-2021-319647

\section{ORCID ID}

Catherine M Otto http://orcid.org/0000-0002-05279392

\section{REFERENCES}

1 Garbi M. National Institute for health and care excellence clinical guidelines development principles and processes. Heart 2021;107:949-53.

2 Otto CM, Kudenchuk PJ, Newby DE. Cardiovascular professional societies fall short in providing impartial, clear and evidence-based guidelines. Heart 2021;107:940-2.
3 Brouwers MC, Kerkvliet K, Spithoff K, et al. The agree reporting checklist: a tool to improve reporting of clinical practice guidelines. BMJ 2016;352:11152.

4 Camm AJ, Fox KAA, Virdone $S$, et al. Comparative effectiveness of oral anticoagulants in everyday practice. Heart 2021:107:962-70.

5 Choi E-K, Lee S-R. Do we need more evidence for oral anticoagulants in everyday practice? Heart 2021;107:943-4.

6 Myerson SG. Community prevalence, mechanisms and outcome of mitral or tricuspid regurgitation. Heart 2021:107:1003-9.

7 Bouleti C, lung B. Atrioventricular valve regurgitation: still a long road ahead. Heart 2021;107:947-8.

8 Lindholt JS. When and why to screen for CVD in healthy individuals. Heart 2021;107:1010-7.

9 Schofield R, Menezes L, Underwood SR. Nuclear cardiology: state of the art. Heart 2021:954-61.

10 Birkhoelzer SM, Gardner FJE, Ortega RF, et al. Pregnancy during cardiology training: a call to action. Heart 2021;107:1018-9. 